\title{
Opinion
}

\section{Medicare for All}

\author{
GAIL R. WILENSKY
}

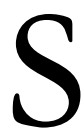

UPPORT FOR "MEDICARE-FOR-ALL" IS BECOMING A DEFINING political issue for Democrats in 2020. Although a few individuals have recently withdrawn their names from consideration for the Democratic presidential nomination—such as Michael Bloomberg, Sherrod Brown (D-OH), Eric Holder (former Attorney General under President Obama) and Jeff Merkley (D-OR)-at least 20 others remain in the race. All of the announced candidates have embraced some form of a Medicare for All or other type of universal coverage program.

Not surprisingly, the term "Medicare for All" is being used differently by the different candidates, as well as by different factions of the Democratic Party. Sometimes the term is used more as a goal of universal coverage rather than a specific program. Other times people use the term when they mean Medicare for more people than are currently covered by the program. Most often, the progressives in the Democratic Party that are using the term mean that every American would be covered by a single-payer government program, as in the Sanders proposal (I-VT) from the 2016 campaign. ${ }^{1}$

Congresswoman Pramila Jayapal (D-WA), cochair of the Progressive Caucus, introduced a Medicare for All bill in the House of Representatives late in February and there is an expectation that the Rules Committee will hold a hearing on her bill this spring. Although it is not that unusual, her bill, which was sponsored by approximately 100 progressives in the House, was not introduced with an estimated cost or a means of funding it.

The Jayapal Medicare for All bill is similar to the Sanders bill from 2016 and provides that every American would be covered by the same, single-payer health plan. The plan provides coverage for all health care, including long-term care, prescription drug care, and dental care, and has no premium payments, coinsurance payments, or deductibles. There is no example of a universal health care system anywhere in the world that

(c) 2019 Milbank Memorial Fund. Published by Wiley Periodicals Inc. 
is structured like this, so it is hard to know what kinds of challenges it would pose. Also, since there are no estimates of what this would cost, it's difficult to know if people would end up spending more, the same, or less in the aggregate on health care. How people would fare individually would depend on the kind of coverage they currently have, what it costs them, and how much they spend on health care beyond their coverage.

There seems to be little memory of how much "push-back" occurred from the American public when the first ACA sign-up period started in the fall of 2013 and some people discovered that their existing health plans were no longer going to be available to them. Although most people were not affected by the ACA, because they were already covered by group plans or existing public programs, most of those who had individual coverage before the ACA were affected. They soon realized that, despite what they had heard from President Obama- "if you like your plan, you can keep your plans and if you like your doctor, you can keep your doctor" - they might be forced to change plans because their former plan was no longer eligible for coverage, and they also might be forced to change physicians if their physicians were not part of the network newly available to them. People may complain about their coverage and how much their plans or prescriptions cost them, but are frequently wary of someone trying to take away what they have without their explicit permission.

Perhaps the mood of the country has so changed as a result of the Trump presidency that this precedent of trying to take away something people have been used to having without their explicit permission to do so will no longer occur but I would be wary. The American public can be very fickle in their support. Reasons for concern about how supportive the American public would actually be if Medicare for All legislation were adopted is reflected in contradictory polling that suggests that while most Americans say they support Medicare for All, they also think that their coverage wouldn't be affected. ${ }^{2}$ Since Medicare for All legislation eliminates private insurance, these two beliefs are inconsistent but, at the moment, no one with a credible voice is trying to disabuse the public of their inconsistent beliefs.

David Brooks wrote a recent column in which he saw the overriding challenge to a Medicare for All world as getting from "here" to "there"given our mix of public and private insurance and the enormity of the transitions that would need to occur. ${ }^{3}$ Patients would have to transition; 
insurance companies would go out of business and take the 540,000 jobs that now exist in the industry with them; and doctors, hospitals, and the American public all would have to transition to a new single-payer world.

There are other options to expand Medicare coverage that are being raised by Democrats aside from Medicare for All, although none is currently receiving the amount of attention that the proposals from the progressives are receiving. These can be grouped under the phrase "Medicare for More."

Medicare for More would result from lowering the eligibility age from the current 65 by providing the population over age 50 with a buy-in option for Medicare. Senator Merkley (D-OR) has advocated for a Medicare-based public option that would allow individuals and employers to buy Medicare coverage. Senators Kaine (D-VA) and Bennet (D-CO) would only allow individuals to purchase Medicare rather than employers. ${ }^{4}$ How much the average person would have to pay under these arrangements is not clear, nor is the end result, although the presumption is that the current stake holders-hospitals, insurers, and drug companies-would stand to lose since they would move from a world where the private sector makes decisions regarding pricing (although in a relatively heavily-regulated industry) to the administered pricing world of Medicare.

There has been speculation that some of the promotion of Medicare for All is really a strategy to help promote the future passage of a public option by making it seem like a more moderate next step. I don't think this is the case for the progressives that are dominating so much of the media attention but it may well be a fall-back position being contemplated by Democratic strategists. Even the Medicare for More option is likely to require an administration with a Democratic president and at least one, if not both, houses of Congress controlled by Democrats as well. In a recent Health Affairs blog, Billy Wynne, who had been on the Democratic staff of the Senate Finance Committee in 2006, raised the notion of introducing a Medicare fall-back option by using Section 1332 waiver authority from the ACA that is modeled after the bill introduced by Kaine and Bennet. ${ }^{5}$

Whatever strategy is chosen, it is likely to be challenged at some stage in the courts. 


\section{References}

1. Debenedetti G. Sanders, Clinton clash over his new 'Medicare for All' plan. Politico. January 17, 2016. https://www.politico. com/story/2016/01/bernie-sanders-health-plan-217906. Accessed March 15, 2019.

2. Pramuk J. House Democrats unveil a sweeping 'Medicare-for-All' bill — here's what's in it. CNBC. February 27, 2019. https://www. cnbc.com/2019/02/27/democrat-pramila-jayapal-introduces-Medi care_for_All-health-care-bill.html. Accessed March 15, 2019.

3. Brooks D. 'Medicare for All': the impossible dream. New York Times. March 4, 2019. https://www.nytimes.com/2019/ 03/04/opinion/Medicare for All.html. Accessed March 15, 2019.

4. Bennet, Kaine introduce Medicare- $\mathrm{X}$ to provide low-cost, high quality care in every zip code [press release]. Denver, CO: Office of Senator Michael Bennet. October 18, 2017. https://www.bennet.senate.gov/public/index.cfm/2017/10/bennetkaine-introduce-medicare-x-to-provide-low-cost-high-qualitycare-in-every-zip-code. Accessed March 15, 2019.

5. Wynne B, Llamas A. Medicare for All can begin in 2021: here's how. Health Affairs Blog. February 28, 2019. https://www.healthaffairs.org/do/10.1377/hblog20190228.9682 46/full/. Accessed March 15, 2019.

Address correspondence to: Gail R. Wilensky, Project HOPE, 7500 Old Georgetown Rd, Ste 600, Bethesda, MD 20814 (email: gwilensky@ projecthope.org). 